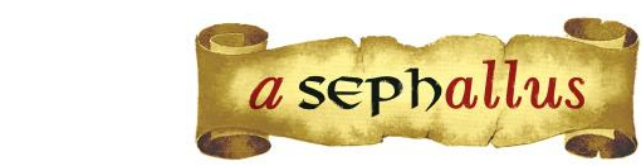

Revista aSEPHallus de Orientação Lacaniana

Núcleo Sephora de Pesquisa sobre o Moderno e o Contemporâneo

ISSN $1809-709 \mathrm{X}$

\title{
Das Ding e o infantil em Freud ${ }^{1}$
}

Karina Carvalho Veras de Souza

Doutoranda em Psicologia pela UFRN - Universidade Federal do Rio Grande do Norte/Programa de Pósgraduação em Psicologia - Centro de Ciências Humanas Letras e Artes - CCHLA. Mestre em Psicologia Clínica pela Universidade Católica de Pernambuco - UNICAP Docente do curso de Psicologia da Universidade Potiguar - UnP E-mail: kaveras@hotmail.com

Resumo: A proposta desse artigo é examinar a articulação entre o conceito freudiano de Coisa - das Ding - e a concepção psicanalítica de infantil. O percurso teórico parte do artigo Projeto para uma Psicologia Científica (1950/1996) no qual Freud delimita o conceito de Coisa - das Ding -, concebendo-o como dimensão indizível da condição humana. Em seguida, esse conceito é articulado ao infantil, que é definido na psicanálise como elemento psíquico inconsciente, decorrente da primeira experiência de satisfação vivida na relação com o Outro. Nessa conjuntura, o infantil é considerado atributo da sexualidade do sujeito. Discutimos, portanto, que o infantil é a estrutura psíquica que possibilita uma expressão discursiva para aquilo que, do ser, é sempre indizível - a Coisa, das Ding.

Palavras-chave: psicanálise; das Ding; inconsciente; infantil; sujeito; estrutura.

\section{Das Ding et l'infantile chez Freud}

La proposition de cet article est d'examiner l'articulation entre le concept freudien de Chose - das Ding - et la conception psychanalytique de I' infantile. Le parcours théorique part de l'article Projet pour une Psychologie Scientifique (1950/1996), dans lequel Freud délimite le concept de Chose-das Ding, en le concevant comme dimension indicible de la condition humaine. En suite, ce concept est articulé à l'infantile, qui est défini dans la psychanalyse comme un élément psychique inconscient découlant de la première expérience de satisfaction vécue dans la relation avec l'Autre. Dans cette conjoncture, l'infantile est considéré comme attribut de la sexualité du sujet. Nous discutons, donc, que l'infantile est la structure psychique qui permet d' exprimer pour ce qui est toujours indicible de l'être - la Chose, das Ding.

Mots-clé: psychanalyse; das Ding; inconscient; infantile; sujet; structure.

\section{Das Ding and infant in Freud}

This article analyze the articulation between the Freudian concept of Thing - das Ding - and the psychoanalytical conception of the infantile. The starting point of the present theoretical course is in the article Project for a Psychological Science (1950/1996) in which Freud establishes the concept of Thing - das Ding, determining it as an unspeakable dimension of the human condition. Then, this concept is linked to the idea of the infantile, which is defined in Psychoanalysis as an unconscious psychical element, due the first experience of satisfaction experienced in the relation to the Other. In this circumstance, the infantile is considered an attribute of the subject's sexuality. We discuss, therefore, that the infant is the psychic structure that enables a discursive expression for whatever that, is always unspeakable of the being - the Thing, das Ding.

Keywords: psychoanalysis; das Ding; unconscious; infant; subject; structure. 


\title{
Das Ding e o infantil em Freud
}

\author{
Karina Carvalho Veras de Souza
}

\section{Introdução}

Para examinar a articulação entre a concepção freudiana de Coisa (das Ding) e o conceito psicanalítico de infantil, enfatizaremos em das Ding sua referência à origem do ser humano e destacaremos o infantil como marca psíquica inconsciente do Outro na constituição do sujeito. Das Ding é o indizível da condição prematura do homem, aquilo que está fora da linguagem, mas que por isso mesmo pode precipitar certo dizer pelo sujeito. Assoun adverte que não se trata de o inconsciente fornecer uma linguagem à Coisa, mas ao contrário, é pelo fato da Coisa não poder ser dita que se constitui "numa espécie de sedimentação, em tema de fala" (Assoun, 1996, p. 108). Quanto ao infantil, será aqui discutido como elemento estrutural, na medida em que é rastro da entrada do sujeito na linguagem. Desse modo, na condição de um dizer, questionamos de que modo o infantil se articula como discurso inconsciente que se oferece como possibilidade de contornar 0 indizível do sujeito. Dito de outra forma, interrogamos em que medida o infantil pode ser tomado como estrutura psíquica que recobre a dimensão enigmática do sujeito, a que o conceito de Coisa (das Ding) faz referência.

\section{Das Ding}

Na obra de Freud, a Coisa é um conceito descrito e problematizado no artigo "Projeto para uma Psicologia científica", escrito em 1895, mas tardiamente publicado, em torno de cinquenta anos depois, quando encontrado em meio às cartas de Freud a Fliess. Esse artigo revela a intenção de Freud de delimitar a origem da organização psíquica do ser humano. Permanece no centro desse escrito a tentativa de compreender como o aparelho psíquico se estrutura e como funciona, representando certo entendimento sobre o que é a subjetividade humana, originada das primeiras experiências de satisfação que construirão depois os afetos e o desejo.

Segundo as notas do editor inglês ${ }^{2}$ que precedem o artigo do "Projeto...", nas correspondências à Fliess, Freud revela duas intenções relativas ao que ele denominava inicialmente de "Psicologia para neurologistas". Primeira, descobrir como permaneceria a teoria do funcionamento psíquico caso fosse introduzida uma abordagem quantitativa; segunda, extrair da psicopatologia o que pudesse ser de utilidade para o que ele chamava de psicologia normal. Vejamos as palavras de Freud na introdução desse trabalho: "A intenção é (...) representar os processos psíquicos como estados quantitativamente determinados de partículas materiais especificáveis, tornando assim esses processos claros e livres de contradição" (Freud, 1950/1996, p. 347). Ainda conforme as notas do editor, Freud vai revelando a Fliess os impasses e angústias que a escrita do artigo Ihe trazia. Afirma ao amigo que seu intento inicial era compreender a defesa patológica, mas que ao longo de suas 
reflexões foi se deparando com o fato de que, na verdade, estava "tentando explicar algo que pertence ao próprio núcleo da natureza" (Freud, 1950/1996, p. 336).

Com efeito, em várias seções do mencionado artigo, Freud imprime certo caráter enigmático em relação à condição perceptiva do sujeito, como, por exemplo, naquela em que trata da Cognição e pensamento reprodutivo. Nessa seção Freud fala sobre o investimento no objeto desejado e sua relação com a realidade. Discorre sobre o complexo perceptual composto de dois neurônios: $a$ e $b$. Assim, nomeia de Coisa o que ele classifica como neurônio a, de estrutura constante. E o outro componente, chama-o de neurônio b, o predicado da Coisa, de estrutura variável (Freud, 1950/1996, p. 380).

Na seção seguinte a essa, que classifica de Memória e juízo, Freud acrescenta a discussão sobre a relação do sujeito com seu semelhante, uma experiência denominada por ele de Nebenmensh - o outro próximo -, ressaltando que é "em relação a seus semelhantes que o ser humano aprende a conhecer" (Freud, 1950/1996, p. 383). Dessa maneira, o outro assume uma condição de primeiro objeto de investimento do sujeito. Freud diz que "o complexo do ser humano semelhante se divide em dois componentes, dos quais um produz uma impressão por sua estrutura constante e permanece unido como uma coisa, enquanto o outro pode ser compreendido por meio da atividade de memória" (Freud, 1950/1996, p. 384). Mais adiante, na seção intitulada Pensamento e realidade, Freud trata da formação do juízo de realidade, situando em sua base as experiências corporais. Defende a ideia de que se trata de um processo associativo envolvendo investimentos em eventos internos e externos ao próprio corpo do sujeito. Em suas considerações, afirma então que "o que chamamos de coisas são resíduos que fogem de serem julgados" (Freud, 1950/1996, p. 386). Trata-se de uma condição humana originada e ancorada nas primeiras experiências corporais em presença de outro. Essa condição escapa a toda e qualquer delimitação objetiva da subjetividade. Como algo que não se descreve na relação com o semelhante, mas que, no entanto, torna-se o âmago da organização psíquica.

Para Freud, a Coisa se origina na primeira experiência de satisfação vivida pelo bebê. Tratase de uma vivência que se constitui em função da prematuridade própria do homem ao nascer. É em função do que o bebê apresenta de insuficiente para dar conta de sua sobrevivência - seu desamparo original - que ele é conduzido pelo desejo do Outro na provisão de sua necessidade. Essa é a condição pela qual se inscreve um traço mnêmico, como uma imagem de um objeto que trouxe alívio às tensões do vivente, próprias à dimensão orgânica. É então que, a cada vez que o estado de tensão se repetir, a imagem mnêmica do objeto surgirá como uma tentativa de repetir a satisfação originária e assim sanar aquele estado de tensão. Todavia, essa satisfação rememorada já é a notícia da perda que constituiu o objeto. Nessa medida, ele surgirá sempre com o estatuto de perdido, sendo a própria marca dessa primeira perda. Esse objeto é justo a Coisa, das Ding, aquilo que faz referência à origem, ao que nasceu como perdido, à alteridade portanto. Sobre a primeira experiência de satisfação, Freud discorre sobre sua especificidade em outra seção do "Projeto...". 
Afirma então que, pelo fato dessa vivência se constituir a partir do desamparo inicial dos seres humanos, ela é considerada a fonte primordial de todos os motivos morais que "tem as consequências mais radicais no desenvolvimento das funções do indivíduo" (Freud, 1950/1996, p. $370)$.

Para Freud, a experiência de satisfação é um evento no qual o sujeito precisará executar uma atividade no interior de seu corpo, suficiente para remover o estímulo endógeno. Mas, em razão de seu desamparo original, fará isso com ajuda de uma ação específica no mundo externo, vinda do outro. Nesse acontecimento, Freud descreve as consequências para o desenvolvimento das funções do indivíduo, que, em suma, resultam no investimento da percepção do objeto, isto é, na imagem mnêmica dele. Ressaltando a teorização freudiana da primeira experiência de satisfação, Fingermann e Dias (2005) relembram seu lugar central em torno do qual se organiza o psiquismo. Sobre a inscrição do traço mnêmico descrita por Freud, os autores aludem ainda que "localiza o marco do sujeito como espaço de ficção oriunda de uma satisfação inalcançável" (Fingermann \& Dias, 2005, p. 27). Nesse sentido, reportam-se a das Ding como uma espécie de "oco" em torno do qual as alucinações da satisfação perdida se articulam como representações, delimitando o ponto de origem e divisão do sujeito.

A psicanálise trata, por esse motivo, da Coisa, como a Coisa sexual. Foi por ela que nasceu, é dela que Freud se ocupou ao longo de sua obra. Sobre o sexual na vertente psicanalítica, vale fazer aqui uma breve menção à síntese que Freud (1940/1996) descreve na parte I do artigo "Esboço de Psicanálise". Nessa seção, ele enumera seus principais achados sobre a sexualidade, a saber, o fato de que a vida sexual não começa na puberdade, mas desde o nascimento; a necessidade de distinção entre o "sexual" e o "genital"; e a ideia de que a vida sexual inclui como função a obtenção de prazer das zonas do corpo, que depois é direcionada à reprodução, advertindo que nem sempre prazer e reprodução irão coincidir. Dessa forma, Freud rompe com a clássica sexologia, apontando para o lugar que o prazer ocupa na constituição do sujeito. Para Roudinesco (1998), Freud mostrou que a sexualidade era ao mesmo tempo uma disposição psíquica universal, assim como o lugar de uma diferença anatômica, constituindo-se assim como essência da atividade humana.

No texto de Assoun (1996) encontramos que foi em torno da Coisa, como algo opaco e mudo, que Freud elaborou a teoria psicanalítica, ouvindo de seus mestres Charcot e Breuer, que na base da histeria havia um fundamento sexual. Do "genital" apontado por Charcot ao "leito conjugal" descrito por Breuer em lugar de "segredo de alcova", Freud aventurou-se em direção à Coisa sexual para dela derivar um saber. Nas palavras de Assoun (1996), o pai da psicanálise se ocupou da Coisa inserindo-a num sistema de verdades de tal modo que ela se tornou "o objeto e o referente de uma discursividade, e não mais de uma simples invocação" (Assoun, 1996, p. 104). Acrescenta que, em razão disso, a psicanálise é uma formalização sobre a Coisa transformada em saber. De que era composta então? Os mestres não avançaram sobre esse ponto. Ao contrário deles, Freud sim... Dessa Coisa quis saber mais. 
Importante observar com Andrès (1996) que o conceito de Coisa enquanto remetido à lógica da origem do sujeito, está atravessado pela visão filosófica de Kant e Heidegger. É por causa disso que o caráter da Coisa (das Ding) como origem irá articular-se ao impensável, ao que não se nomeia. Todavia, justamente por essa condição, o indizível impele o sujeito a uma busca, ao mesmo tempo, impossível e incansável, que é a de tentar dar alguma consistência à Coisa.

Em Lacan (1959-1960/1997), o conceito freudiano de Coisa está problematizado no capítulo IV de seu seminário 7, seção intitulada das Ding. Da mencionada seção, importa ora sublinhar a vinculação que Lacan estabelece entre a Coisa e o princípio de realidade, teorizado por Freud no "Projeto". Logo no início Lacan afirma que das Ding se situa em outro lugar, aquele que não é relativo ao campo do explicável e que faz o homem se referir às coisas que são criadas pelas palavras. Ele sustenta que o que há em das Ding é absolutamente outra coisa, a saber, que ela comporta o que ele denomina de segredo sobre o princípio de realidade. Nessa correlação, Lacan afirma que das Ding é uma realidade que ordena, que comanda, mas à qual ele atribui a designação de "realidade muda" (Lacan, 1959-1960/1997, p. 72). Sobre essa definição, esclarece que o que está em questão para o sujeito em sua primeira experiência da realidade são as coisas na condição de serem mudas. Vejamos a advertência que Lacan faz sobre isso: "as coisas mudas não são exatamente a mesma coisa que as coisas que não tem relação com as palavras" (Lacan, 1959-1960/1997, p. 72).

Com isso, Lacan (1959-1960/1997) nos ensina que a Coisa só se apresenta ao sujeito quando localizada numa trama significante, "quando ela acerta na palavra, como se diz acertar na mosca" (Lacan, 1959-1960/1997, p. 72). Nesse entendimento, das Ding é situada por ele como aquilo que é "fora-do-significado". Mas, ao mesmo tempo, Lacan acrescenta que é em função desse lugar que o sujeito, ao conservar sua distância, constitui-se no mundo de relação. Nas palavras dele: "O Ding é o elemento que é, originalmente, isolado pelo sujeito em sua experiência no Nebenmensch, como sendo por sua natureza, estranho, Fremde' (Lacan, 1959-1960/1997, p. 68). Trata-se do primeiro exterior do sujeito.

Desse modo, na medida em que das Ding se apresenta como o estranho, inaugura ao seu redor o movimento da representação guiado pelo princípio do prazer. Consequentemente, a Coisa será identificada à tendência ao reencontro do objeto. É o indício do perdido, situando-se fora do campo da representação. Seguem as palavras de Lacan sobre esse reencontro: "Reencontramo-lo no máximo como saudade" (Lacan, 1959-1960/1997, p. 68).

A observação de Coutinho Jorge (2005) é de que não se trata de situar o objeto, mas de considerar os sucessivos reencontros com ele, sempre como perdido. Ou seja, encontrar o objeto é então reencontrá-lo sem encontrá-lo, resume o autor. Isso quer dizer que o caráter faltoso estará sempre lá, a cada vez que o sujeito reencontrar o objeto. Nesse cenário, do alto de sua condição de vazio que não se preenche e não se diz, a Coisa leva à criação. Aí, como diz Rudge (1998), ela é bússola, estrutura que dirige a escolha dos objetos fazendo o sujeito nadar por entre o mar de seus significantes. A autora afirma então que o resgate da Coisa visa um ponto paradoxal, ao mesmo 
tempo central e exterior: a extimidade - termo mencionado por Lacan em seu seminário 7 como sendo "esse lugar central, essa exterioridade íntima, essa extimidade, que é a Coisa" (Lacan, 19591960/1997, p. 173).

Para Wine (1992), a exterioridade íntima lacaniana produz o estranho familiar do sujeito. Nesse sentido, na tentativa de atingir a Coisa, a autora diz que avançamos revendo sua ausência a cada investida, "de fracasso em fracasso" (Wine, 1992, p. 145). É aí que a Coisa pode derivar um marco mítico sobre o qual tecemos com significantes nossa condição de sujeito. Mas, como a Coisa se articularia ao infantil do sujeito? Como se atam? Atam-se? Seria assim que o infantil daria as pistas de nossa divisão originária, trazendo um aceno da Coisa? Que saber existiria aí?

\section{O infantil}

Quando Freud advertiu o mundo de que a criança tinha uma sexualidade, não disse apenas que a sexualidade está presente em sua condição, mas também que seu atributo é infantil e permanece no sujeito para além do fato de que ela se torne adulto. 0 infantil, nesse caso, não é relativo apenas ao que ocorre no tempo cronológico da fase da infância. Tampouco se trata de um adjetivo que alude à falta de maturidade, aquela determinada pelo imaginário. No clássico texto dos "Três ensaios sobre a teoria da sexualidade", de 1905, Freud retoma um ensinamento iniciado desde o "Projeto", a saber, o fato de que as primeiras experiências de satisfação deixam marcas psíquicas inconscientes, levando o sujeito a constituir, em seu desejo, um objeto que permita percorrer essas marcas. Esse é o elemento infantil, aquele que introduz o sujeito na linguagem pelas vicissitudes da complexa relação com o Outro. São marcas psíquicas que não passam, constituirão demanda e não são superáveis com o avanço dos anos, não há nada a superar, nem a evoluir, mas a tramar com significantes. Vejamos as seguintes palavras de Elia (1995):

Infantil não porque ocorre na infância, embora ali de fato ocorra. Infantil como é para Freud toda sexualidade, em qualquer tempo biográfico em que a captemos, na trajetória existencial do sujeito humano. (...) Freud batizou de infantil a sexualidade que conceitualizou a partir da clínica, afirmando (...) a sua exclusividade: (...) só existe, do ponto de vista psicanalítico, (...) a sexualidade do falante. (Elia, 1995, p. 57)

Nessa seara, o infantil psicanalítico faz alusão ao que é estrutural na condição de sujeito. E na medida em que é condição psíquica, o infantil vai se tornando referente, aderindo ao Real de sua existência. Torna-se inscrição inconsciente, marca de satisfação que constitui os fundamentos de nossa subjetividade desejante. Isso quer dizer que o infantil não se regula pela lógica do desenvolvimento, não se reduz à concretude das experiências. Não diz da contagem da idade, mas do que se conta com um discurso que ultrapassa o próprio eu. A estrutura da temporalidade 
inconsciente é então sua marca. O infantil freudiano é, por assim dizer, constituído pelas marcas dos significantes do Outro, os traços dele que fixam para o sujeito os índices de suas experiências de satisfação.

Sendo então toda sexualidade infantil, é possível nomeá-la como um fazer e um lugar de onde contornar a opacidade da Coisa? A noção freudiana de "lembranças encobridoras" talvez permita uma reflexão nesse sentido. As cenas da infância, as imagens..., sejam fortuitas, claras, nebulosas, vivas, fugazes, repugnantes, nostálgicas, cheias ou vazias de detalhes, como quer que elas sejam, compõem a trama do nosso infantil porquanto trazem a marca do Outro. Por isso, não há cena que resuma a infância, não há sequência lógica nessa rememoração; há sim, cenas que deixam pistas da Coisa sexual que deu margem ao infantil e à sua estruturação. É o tecido de nosso vivido que vela e revela por seus nós, laços e bordados, o modo como tentamos lidar com a Coisa sexual. Com o infantil tecemos um manto para atravessar o vazio e inefável dela.

Em seu texto "Posição do inconsciente" Lacan (1960-1964/1998) acentua o lugar do Outro para o sujeito, a saber, como causa significante deste. Assim sendo, a afirmação de que nosso infantil traz a marca do Outro revela a base da relação significante. Essa relação, constituída pelas operações de alienação e separação, tem como resultado a causa do próprio sujeito. Sendo assim, Lacan nos diz que:

[...] nenhum sujeito tem razão de aparecer no real, salvo por nele existirem seres falantes. Concebe-se uma física que dê conta de tudo no mundo, inclusive de sua parte animada. Um sujeito só se impõe nela por haver no mundo significantes que não querem dizer nada e que têm que ser decifrados. (Lacan, 1960-1964/1998, p. 854)

Assim, tecemos nosso infantil com os significantes do Outro com a prerrogativa de que tomar posse deles será uma possibilidade. Sauret (1998) comenta que a criança deve sua sobrevivência e sua relação com a linguagem ao Outro que se ocupa dela. Isso quer dizer que ser recebida como objeto de desejo da mãe é a condição que garantirá à criança sua inscrição no campo da linguagem. É assim porque o Outro materno transforma o grito da necessidade da criança em apelo, articula-o a uma demanda. Nessa direção, a autora lembra que a experiência inaugural de insatisfação da criança, que é a provação da fome, é marcada pela ausência de significantes. Condição que instaura a falta fundamental, introduzindo o enigma da questão: "O que o Outro quer de mim?". Pois é o Outro quem fornece à criança os significantes com os quais ela significará sua experiência. Conforme nos ensinou Lacan, esse "empréstimo" valerá como seu ingresso para o universo simbólico, lugar de onde o sujeito falará, na tentativa de responder ao desejo do Outro, sempre por um "meio dizer". Como resumiu Elia (1995), o infantil define o modo próprio de ser sexual dos seres falantes, conjugando pulsão e linguagem. 
A infância da criança difere, portanto, do infantil do sujeito, disso não há dúvida. A infância é consistência temporal na qual a criança tem uma idade, é um ator e protagonista, por isso se desenvolve. Já o infantil é o véu da fantasia sobre o vazio original da Coisa. Seu tempo é Outro, é de Outra coisa que se trata. Nele, quem habita é o sujeito do inconsciente, sem idade. O tempo da infância é configuração do infantil do sujeito. Trata-se de uma miragem necessária, bem na medida do nosso imaginário. Dizemos: "nossa infância foi assim ou de tal modo...". Com a infância contornamos nosso infantil, bordamos em sua complexa trama nossos jardins secretos, desenhamos sóis ardentes e nuvens espessas, daquelas que podem produzir tempestades e raios. Com isso produzimos um saber aí, nossa verdade. Coetzee, em seu livro "Infância", ao mencionar seu personagem Jonh diz:

A infância, segundo a Enciclopédia das crianças, é uma época de felicidade inocente, que se vive nas campinas entre flores e coelhos, ou junto à lareira absorto num livro de contos. É uma visão da infância alheia a ele. Nada do que vive em Worcester, em casa ou na escola, o faz pensar que a infância seja mais do que uma fase de engolir seco e suportar. (Coetzee, 2010, p. 16)

Talvez seja isso então: suportar a Coisa sexual. "Engoli-la a seco" pode ser uma saída. A infância faz uma marca no tempo vivido pelo sujeito, mas o infantil é a realidade psíquica constituída em função de uma anterioridade sem nome, tomada em sua incompletude e caráter mítico: a Coisa. Desse lugar, um dizer e um saber torna-se possível para o sujeito. Trata-se de uma verdade desenhada pela lógica do inconsciente. Nesse sentido, se a infância é uma fase da vida deixada para trás em um dado momento da realidade comum, não podemos dizer o mesmo quanto ao infantil. Nesse caso, não se trata de um estágio, mas de uma estruturação psíquica inconsciente. Por isso é imune à passagem do tempo. Às vezes engole e suporta, como o personagem Jonh em Coetzee. 0 infantil como marca da Coisa é efeito do objeto que nunca esteve lá, mas que justo por essa condição é um primeiro tempo de edificar numa bela ou trágica trama, uma estrutura feita de significantes.

\section{A dimensão estrutural do infantil}

Embora o conceito formal de estrutura não tenha sido uma construção freudiana - como foi no ensino de Lacan -, quando o situou no campo da linguagem, Meira (2004) observa que desde Freud já é possível encontrar subsídios que tocam a concepção de estrutura psíquica. A autora relaciona alguns artigos de Freud, tais como: "Neuropsicoses de defesa", de 1894; "Neurose e psicose", de 1924 e o "Fetichismo", de 1927, cuja discussão freudiana envolve os mecanismos de defesa inerentes aos diferentes quadros clínicos, evidenciando uma concepção estrutural em jogo. Assim, ao discutir o recalque na neurose, a rejeição na psicose e o desmentido na perversão, 
vislumbra-se em Freud uma discussão quanto à diversidade dos arranjos psíquicos no tocante a tais modalidades clínicas.

Nas palavras de Meira (2004), a estrutura é, por isso, uma manifestação do significante, da linguagem. Nessa medida, as estruturas clínicas são "modos de resposta à questão do desejo do Outro" (Meira, 2004, p. 126). No entanto, a autora adverte que a estrutura ultrapassa o significante, pois algo da própria composição estrutural é da ordem do Real. Isso quer dizer que algo sempre escapará ao recobrimento do significante, será o vazio que a invenção simbólica de cada um vai tentar fazer função de suplência.

Em nosso artigo, para além da formalidade lacaniana que define e discute as estruturas clínicas por suas complexas modalidades discursivas, destacamos aqui uma concepção mais ampla de estrutura. Trata-se, em linhas gerais, de um modo próprio que o sujeito elabora para lidar com sua falta estrutural, como pontua Meira (2004). É desse modo que situamos o infantil: um arranjo significante com o qual se possa fazer frente ao ponto de vazio da estrutura.

\section{Discussão}

Situar o infantil como uma trama significante é evidenciá-lo como estrutura psíquica e, como tal, considerar que um saber inconsciente amarra-o simbolicamente à Coisa. 0 discurso do sujeito revelará, portanto, as disposições inconscientes dessa estrutura. Ela é de algum modo o mito que o sujeito empreende, ou seja, a maneira com a qual ele pode fazer frente ao perdido de sua origem, ao que o antecedeu no desejo do Outro. Vale destacar aqui as palavras desde Freud (1914/1996), quando, por ocasião do artigo "Sobre o narcisismo: uma introdução", ao tratar de sua teoria sobre o narcisismo primário, afirmou: "A criança concretizará os sonhos dourados que os pais jamais realizaram" (Freud, 1914/1996, p. 98). Assim, o narcisismo dos pais renasce na criança, e na medida em que antecipam certa imagem dela, é em relação ao narcisismo de seus genitores que a criança responde, constituindo-se como sujeito. Ela é falada desde antes de nascer, seja pela escolha de seu nome, pela idealização de suas características físicas, ou pela interrogação de seu sexo: se será menino ou menina. Essa é a história que precede o nascimento da criança e na qual ela precisará se posicionar quanto aos significantes que a antecederam. Com efeito, Lacan nos ensina que o sujeito "não é causa dele mesmo, mas traz em si o germe da causa que o cinde" (Lacan, 1964/1998, p. 849), pois "se isso fala dele, é aí que ele se apreende" (Lacan, 1964/1998, p. 849).

Sobre essa apreensão do sujeito, Saldanha (2015) comenta que é na fala que a criança pode se "historizar", passando da condição de interpretada pelo Outro à intérprete de si e de seu desejo, reescrevendo sua história própria. Trata-se do tempo de efetuação da estrutura, quando a criança formula teorias para lidar com seus próprios enigmas, já que, na busca incessante pela verdade, o Outro também vacila em seu saber. As teorias sexuais infantis serão os "produtos da criançaintérprete" (Saldanha, 2015, p. 252). Sauret (1998) observa que o sujeito é contável pelo que diz em sua condição própria de linguagem, em seu ritmo. A mesma autora diz que não se trata 
simplesmente do fato de que "a verdade sai da boca das crianças" (Sauret, 1998, p. 23), mas de considerar que só há sujeito quando algo se põe a falar sobre a falta na estrutura.

É por uma função de amarração simbólica, portanto, que talvez seja interessante situar o infantil em relação à Coisa. Quando o sujeito toma a falta para si, assume-a nas muitas formas de seu discurso inconsciente. Assim, o lidar com seu enigma é a aventura primordial da qual o sujeito não só não pode fugir como foi por ela que desabrochou como falante. É com a estrutura de seu infantil que o sujeito avança bordejando a Coisa, abrindo caminho para dar consistência a outras possibilidades significantes. $O$ fato de a Coisa ser limite da própria linguagem é, talvez, aquilo que oferece alguma garantia de que o infantil possa ladear e sustentar a ex-sistência do sujeito.

\section{Notas:}

${ }^{1}$ Este trabalho está inserido na pesquisa de doutoramento junto ao Programa de Pós-Graduação em Psicologia - Centro de Ciências Humanas Letras e Artes/CCHLA da UFRN - Universidade Federal do Rio Grande do Norte, orientada pela Profa Dra Rosângela Franscischini.

${ }^{2}$ Comentários encontrados na Introdução do Editor Inglês das Obras psicológicas completas de Sigmund Freud. Edição standard brasileira traduzida pela Imago Editora, (Vol. 1, pp. 335-346).

\section{Referências Bibliográficas}

Andrès, M. (1996). Coisa. In Kaufmann, P., Dicionário enciclopédico de psicanálise: o legado de Freud a Lacan (pp. 84-85). Rio de Janeiro: Jorge Zahar.

Assoun, P. (1996). A Coisa: metapsicologia e psicossexualidade. Metapsicologia freudiana: uma introdução (pp. 96-126). Rio de Janeiro: Jorge Zahar.

Coetzee, J. M. (2010). Infância: cenas na vida da província. São Paulo: Companhia das Letras.

Coutinho Jorge, M. A. (2005). O objeto perdido do desejo. Fundamentos da psicanálise: de Freud a Lacan. Vol. 1: As bases conceituais (pp. 139-158). Rio de Janeiro: Jorge Zahar.

Elia, L. (1995). Sexualidade e Psicanálise. Corpo e sexualidade em Freud e Lacan (pp. 39-80). Rio de Janeiro: Uapê.

Fingermann, D. \& Dias, M. M. (2005). O nome e o pior. Por causa do pior (pp. 21-40). São Paulo: Iluminuras.

Freud, S. (1996). Três ensaios sobre a teoria da sexualidade. Edição standard brasileira das obras psicológicas completas de Sigmund Freud (Vol. 7, pp. 119-231). Rio de Janeiro: Imago (Trabalho original publicado em 1905).

Freud, S. (1996). Sobre o narcisismo: uma introdução. Edição standard brasileira das obras psicológicas completas de Sigmund Freud (Vol. 14, pp. 75-108). Rio de Janeiro: Imago (Trabalho original publicado em 1914). 
Freud, S. (1996). Esboço de psicanálise. Edição standard brasileira das obras psicológicas completas de Sigmund Freud (Vol. 23, pp. 153-270). Rio de Janeiro: Imago (Trabalho original publicado em 1940[1938]).

Freud, S. (1996). Projeto para uma psicologia científica. Edição standard brasileira das obras psicológicas completas de Sigmund Freud (Vol. 1, pp. 335-454). Rio de Janeiro: Imago (Trabalho original publicado em 1950[1895]).

Lacan, J. (1997). Das Ding. O seminário, livro 7: a ética da psicanálise (pp. 58-90). Rio de Janeiro: Jorge Zahar (Trabalho original publicado em 1959-1960).

Lacan, J. (1997). Posição do inconsciente. Escritos (pp. 843-864). Rio de Janeiro: Jorge Zahar (Trabalho original publicado em 1960-1964).

Meira, Y. M. (2004). A estrutura e a criança. As estruturas clínicas e a criança (pp. 125-130). São Paulo: Casa do Psicólogo.

Roudinesco, E. \& Plon, M. (1998). Sexualidade. Dicionário de Psicanálise (pp. 704-705). Rio de Janeiro: Jorge Zahar.

Rudge, A. M. (1998). Simbolização primordial e fundação do sujeito. Pulsão e linguagem: esboço de uma concepção psicanalítica do ato (pp. 38-55). Rio de Janeiro: Jorge Zahar.

Sauret, M. (1998). A criança, o infantil, o sujeito. O infantil e a estrutura (pp. 7-10). São Paulo: EBP. Saldanha, C. M. T. (2015). A historização da criança em análise. In Silva, J. A. (Org.), Topologia da fala (pp. 246-256). Salvador: Associação Científica Campo Psicanalítico.

Wine, N. (1992). O "não" faz a ponte entre o real e o simbólico. Pulsão e inconsciente: a sublimação e o advento do sujeito (pp. 122-145). Rio de Janeiro: Jorge Zahar.

Citacão/Citation: veras de Souza, K. C. (nov. 2016 a abr. 2017). Das Ding e o infantil em Freud. Revista aSEPHallus de Orientação Lacaniana, 12(23), 99-109. Disponível em www.isepol.com/asephallus. doi: 10.17852/1809-709x.2019v12n23p99-109.

Editor do artigo: Tania Coelho dos Santos.

Recebido/Received: 24/01/2017 / 01/24/2017.

Aceito/Accepted: 01/03/2017 / 03/01/2017.

Copyright: (C) 2013 Associação Núcleo Sephora de Pesquisa sobre o moderno e o contemporâneo. Este é um artigo de livre acesso, que permite uso irrestrito, distribuição e reprodução em qualquer meio, desde que o autor e a fonte sejam citados/This is an open-access article, which permites unrestricted use, distribution, and reproduction in any medium, provided the author and source are credited. 